\title{
A Teoria Crítica da Escola de Frankfurt e a persistência do populismo autoritário nos Estados Unidos*
}

\author{
Frankfurt School Critical Theory and the Persistence of Authoritarian \\ Populism in the United States
}

\author{
John Abromeit \\ abromejd@buffalostate.edu \\ (State University of New York - Buffalo State, New York, United States)
}

\begin{abstract}
Resumo: A primeira parte deste artigo fornece um breve resumo dos estudos sobre o autoritarismo e o populismo de direita dos Teóricos Críticos. A segunda parte analisa a emergência do Tea Party e o sucesso de Donald Trump em expandir e intensificar este movimento populista de direita ao atrelálo à sua liderança autoritária. Com base nos recursos conceituais expostos na primeira seção, pretendo demonstrar na segunda seção como as análises do populismo de direita e do autoritarismo dos Teóricos Críticos ainda podem explicar aspectos chave do Tea Party e de Trump. Ao longo deste artigo, a Teoria Crítica e o populismo de direita são situados em dois níveis de periodização histórica: o primeiro é a época burguesa moderna como um todo e o segundo se refere a períodos específicos desta época. 0 objetivo desta última periodização é esclarecer as condições históricas e sociais específicas que inibiram ou favoreceram o surgimento do populismo de direita e dos movimentos autoritários.
\end{abstract}

Palavras-chave: Teoria Crítica; populismo de direita; autoritarismo; Escola de Frankfurt.
Abstract: The first part of the essay provides a brief overview of the Critical Theorists' studies of authoritarianism and right-wing populism. The second part examines the emergence of the Tea Party and Donald Trump's success in expanding and intensifying this right-wing populist movement by harnessing it to his own authoritarian leadership. Drawing on the conceptual resources outlined in the first section, I seek to demonstrate in the second section how the Critical Theorists' analyses of right-wing populism and authoritarianism can still explain key aspects of the Tea Party and Trump. Throughout this essay Critical Theory and right-wing populism is situated within two levels of historical periodization: first, the modern bourgeois epoch as whole and, second, specific periods within that epoch. The aim of the latter periodization is to illuminate the specific historical and social conditions that have inhibited or favored the emergence of right-wing populist and authoritarian movements.

Keywords: Critical Theory; right-wing populism; authoritarianism; Frankfurt School.

DOI: http://dx.doi.org/10.11606/issn.2318-9800.v22i1p13-38

\section{Introdução}

Embora o crescimento de movimentos e partidos populistas de direita na Europa nas últimas décadas e o mais recente sucesso do Tea Party nos Estados

\footnotetext{
* Esta é uma versão revisada e atualizada do texto publicado no periódico Logos, 15 (2-3) de 2016, sob o título "Critical Theory and the Persistence of Right-Wing Populism" - http://logosjournal. com/2016/abromeit (acesso em 11.06.2017). Traduzido para o português por Simone Fernandes.
} 
Unidos tenham recebido ampla atenção de cientistas sociais, o crescimento contínuo desses partidos na Europa e a recente eleição de Donald Trump como presidente dos Estados Unidos desconcertaram e surpreenderam muitos estudiosos. Há dez anos, poucos estudiosos teriam previsto que partidos populistas de direita estariam governando (como na Hungria e na Polônia); ameaçando governar (como na França e na Suíça); constituindo partidos de oposição poderosos e influentes (como na Áustria, na Holanda, na Dinamarca e na Eslováquia); ou emergindo como uma nova força na política eleitoral (como na Inglaterra, na Suécia, na Finlândia e até mesmo na Alemanha). Há um ano, poucos teriam previsto que os ingleses votariam pela saída da União Europeia e que Donald Trump seria eleito presidente nos Estados Unidos. A seguir, defendo que esta perplexidade generalizada entre os cientistas sociais e a sua dificuldade em explicar o persistente e crescente sucesso do populismo de direita na Europa e nos Estados Unidos revelam pontos cegos teóricos históricos e críticos em seus trabalhos, que poderiam ser enfrentados ao se revisitar a rica obra acerca do populismo de direita e do autoritarismo nos escritos dos integrantes do Instituto de pesquisa social de Frankfurt. Desde o final dos anos 1920 e durante o período do pós-guerra, Max Horkheimer e seus colegas do Instituto produziram uma série de importantes estudos históricos, teóricos e empíricos que podem ainda lançar luz sobre a persistência do populismo de direita e do autoritarismo do século XX até o século XXI.

Este artigo analisará como a Teoria Crítica foi decisivamente moldada durante o exílio nos Estados Unidos nos anos 1930 e 1940. Também analisará como e porque as "experiências científicas" dos Teóricos Críticos nos Estados Unidos ainda são relevantes para explicar acontecimentos sociais e políticos contemporâneos em seu país de exílio. ${ }^{1} \mathrm{~A}$ primeira parte deste artigo fornecerá um breve resumo dos estudos sobre o autoritarismo e o populismo de direita dos Teóricos Críticos. Enfatizarei, em particular, os estudos empíricos realizados nos Estados Unidos nos anos 1940, mas também analisarei alguns conceitos chave da Dialética do Esclarecimento, como o conceito de antissemitismo burguês. A segunda parte deste trabalho analisará a emergência do Tea Party e o sucesso de Donald Trump em expandir e intensificar este movimento populista de direita ao atrelá-lo à sua liderança autoritária. Com base nos recursos conceituais expostos na primeira seção, demonstrarei como as análises do populismo de direita e do autoritarismo dos Teóricos Críticos ainda podem explicar aspectos chave acerca do Tea Party e de Trump que surpreenderam muitos cientistas sociais contemporâneos. Ao longo deste artigo, a Teoria Crítica e o populismo de direita serão situados em dois níveis de periodização histórica. 0 primeiro - que vou

1 Para um relato do próprio Adorno acerca de suas "experiências científicas" nos Estados Unidos, conferir o ensaio "Scientific Experiences of a European Scholar in America" - Adorno, 1969, pp.338370 . 
apenas indicar - é o da época burguesa moderna como um todo. 0 segundo se refere a períodos específicos desta época: em particular, os períodos históricos que coincidem com o surgimento, o declínio e o ressurgimento do populismo de direita, do final do século XIX até o presente. O objetivo desta última periodização é esclarecer acerca das condições históricas e sociais específicas que inibiram ou favoreceram o surgimento do populismo de direita e dos movimentos autoritários.

\section{Revisitando as análises acerca do populismo de direita e do autoritarismo dos Teóricos Críticos}

Os esforços da Teoria Crítica da Escola de Frankfurt para compreender o fascismo foram cruciais para o seu desenvolvimento. Compreendeu-se o fascismo em grande medida como uma forma de populismo autoritário de direita, que alcançou extremos sem precedentes na Alemanha nacional-socialista, mas que não era de modo algum exclusivo da Alemanha. 0 fascismo foi considerado um resultado de poderosas tendências sociohistóricas e sociopsicológicas presentes em todas as sociedades capitalistas avançadas. "Der Fascismus ist kein Zufall gewesen" ["O fascismo não foi uma coincidência"], como Adorno apontou. ${ }^{2}$ Um bom ponto de partida para um reexame da rica obra dos Teóricos Críticos sobre o autoritarismo é o ensaio de Max Horkheimer de 1936, "Egoísmo e movimentos de libertação: para uma antropologia da época burguesa", em que ele analisa as origens históricas do fascismo em termos de uma transformação dos movimentos de protesto populares - que denomina de "movimentos burgueses de libertação" - da esquerda para a direita, correspondendo à transformação histórica da relação da burguesia com as classes mais baixas ocorrida na Europa durante o século XIX e o início do século XX. É importante revisitar o ensaio de Horkheimer não apenas devido ao seu argumento sobre a transformação dos movimentos populares de protesto e a ideologia populista de seus líderes, mas também porque forneceu os fundamentos históricos e teóricos para grande parte do trabalho empírico sobre autoritarismo que o Instituto desenvolveu nos Estados Unidos nos anos 1940. Como aponta Martin Jay, “como solo fértil para boa parte do trabalho posterior da Escola de Frankfurt, é praticamente inigualável” (Jay, 1982, p.5).

No ensaio "Egoísmo...", Horkheimer analisa diferentes lideranças de movimentos sociais populares no início do período moderno, cujas tentativas de mobilizar ou controlar as classes mais baixas consolidaram o poder da sociedade burguesa. Seus estudos de caso são Cola di Rienzo e Savanarola, líderes de movimentos de protesto populares em Roma e em Florença nos séculos XIV e XV; Lutero, Calvino e a Reforma; e Robespierre e a Revolução Francesa. Em cada caso, Horkheimer

2 Em "Vorlesungen zur Ästhetik", 30 de novembro de 1967 - cf. Adorno, 1998a, p.328. 
enfatiza a relação peculiar que se desenvolve entre os líderes burgueses e as classes mais baixas no decorrer desses movimentos. Ele escreve:

Os esforços da burguesia para fazer prevalecer suas próprias demandas por uma administração mais racional contra os poderes feudais e com o apoio das massas populares desesperadas, ao mesmo tempo consolidando seu próprio domínio sobre as massas, se conjugam para explicar o modo peculiar como a luta pelo "povo" é conduzida nestes movimentos (Horkheimer, 1993, pp.61-62).

Por um lado, Horkheimer enfatiza os aspectos genuinamente progressistas desses movimentos sociais, que resultam do interesse compartilhado entre a burguesia e as classes mais baixas em derrotar o regime aristocrático e/ou absolutista. Por outro lado, Horkheimer atenta para os aspectos autoritários destes movimentos, que expressam a incipiente divergência de interesses entre a burguesia e as classes mais baixas. Após as revoluções burguesas dos séculos XVII e XVIII, este conflito de interesses latente emergiria com a ascensão de um vigoroso movimento socialista no século XIX, que desafiaria a nova hegemonia da burguesia. O surgimento do fascismo na Europa dos anos 1920 representou algo qualitativamente novo, na medida em que rompeu com o conservadorismo tradicional do século XIX e envolveu a mobilização do "povo" contra uma ameaça percebida, da esquerda socialista. Observando o crescimento do fascismo na Europa em 1936, Horkheimer escreve:

Os levantes ocorridos no passado mais recente em alguns Estados europeus (...) não são reações absolutistas ou clericais, mas a encenação de uma pseudorrevolução burguesa com ornamentos populistas radicais, totalmente contrária a qualquer possível reorganização da sociedade. As formas que elas tomam parecem ser uma imitação ruim dos movimentos discutidos anteriormente (idem, p.97).

Aqui podemos notar que Horkheimer ressalta os elementos populistas do fascismo, mas também a diferente função que estes elementos desempenham nas modificadas condições sociais e históricas da Europa do começo do século XX. De modo simplificado, pode-se dizer que os elementos progressistas que caracterizaram os movimentos modernos iniciais desapareceram e apenas os seus elementos autoritários permaneceram. ${ }^{3}$

O mais importante para nossos propósitos aqui é que o ensaio de Horkheimer fornece uma análise histórica da transformação do populismo inserida na transformação mais ampla da sociedade burguesa, enfatizando o surgimento de poderosas tendências populistas de direita na Europa no fim do século XIX, que conduziram aos movimentos fascistas bem-sucedidos em vários países europeus nos anos 1920 e 1930. Deve-se parar para refletir sobre o fato de que a própria ideia de

3 Tal análise de Horkheimer da transformação do populismo antecipa estudos históricos mais recentes sobre a relação entre o fascismo e o populismo, de pesquisadores como Peter Fritzsche, Geoff Eley, Ernesto Laclau e Zeev Sternhell. Para uma discussão destes estudos e sua reconceitualização da relação entre populismo e fascismo, ver meu ensaio "Transformations of Producerist Populism in Western Europe" - Abromeit, 2016, pp.231-264. 
um "populismo de direita" deve ter parecido uma contradição em termos naquela época. O populismo e os apelos "ao povo”, “das Volk”, eram um componente básico de movimentos liberais e democráticos do século XIX, e os conservadores tradicionais do século XIX eram fortemente antidemocráticos e antipopulistas. No entanto, por volta do fim do século XIX, eles também acabaram por perceber que a batalha contra a democracia era inútil; se as elites conservadoras esperavam proteger suas posições de poder em uma "era das massas", precisariam aprender a jogar o jogo da democracia, para garantir resultados que lhes fossem favoráveis. ${ }^{4}$ Sintomático da nova estratégia populista de direita foi o arquiconservador Kreuz-Zeitung, que depois da Primeira Guerra Mundial mudou seu mote de "Vorwärts mit Gott für König und Vaterland" [Adiante com Deus para o rei e pátria] para "Für das deutsche Volk [Para o povo alemão]" (Fritzsche, 1999, p.111). Mas, como pesquisas históricas mais recentes têm enfatizado, este novo populismo de direita não era, de modo algum, mera invenção das elites conservadoras. ${ }^{5}$ Tais elites estavam ávidas para manipulá-lo, mas suas origens eram genuinamente espontâneas e populares. Em outras palavras, a emergência do populismo de direita no início do século XX, como uma força social e política qualitativamente nova em sociedades industriais avançadas, deve ser compreendida como uma combinação de ativismo de base genuinamente popular e das tentativas das elites conservadoras de manipular esses movimentos para seus propósitos.

Horkheimer e seus colegas no Instituto estavam interessados nesses dois aspectos do populismo de direita. Já em seu primeiro grande estudo empírico sobre os trabalhadores de colarinho azul e branco nos últimos anos da República de Weimar, Horkheimer e Erich Fromm procuraram determinar o quanto estes trabalhadores eram suscetíveis às tentações dos movimentos políticos autoritários à direita (cf. Fromm, 1983). O estudo indicou que se um movimento como tal tentasse tomar o poder na Alemanha, a resistência desses grupos seria mínima. Seus resultados seriam confirmados poucos anos depois. O próximo grande estudo empírico do Instituto buscou analisar como atitudes autoritárias entre as classes médias e baixas na Europa e nos Estados Unidos eram condicionadas pela estrutura cambiante da família. Para os propósitos deste artigo, gostaria de me deter sobre os estudos empíricos que foram conduzidos nos Estados Unidos na década de 1940, que ilustraram a premissa básica de que o populismo de direita e as tendências sociais e políticas populistas e autoritárias não estavam de modo algum restritas à Alemanha ou à Europa.

\footnotetext{
4 The Crowd: A Study of the Popular Mind, de Gustave Le Bon, que foi publicado pela primeira vez em 1895, é um excelente exemplo desta tendência mais ampla. Le Bon se apresenta ali como um Maquiavel dos tempos modernos, que escreveu um manual político prático para as elites conservadoras, de modo a instruí-las sobre como manipular as massas para manter seu próprio poder. Não por acaso, Mussolini foi um leitor ávido e admirador do trabalho de Le Bon.

5 Para uma discussão mais detalhada dessas pesquisas, conferir referência da nota 3.
} 
Mas, antes de passar à discussão de alguns resultados desses estudos, gostaria de examinar brevemente a mudança de paradigma na Teoria Crítica por volta dos anos 1940. Esta mudança refletiu as transformações socioeconômicas, histórias e políticas mais amplas que ocorreram na Europa e nos Estados Unidos no decorrer dos anos 1930. De modo sucinto, pode-se dizer que a Grande Depressão conduziu ao colapso final da antiga ordem econômica liberal e à ascensão de novas formas de capitalismo centradas no Estado na Europa. ${ }^{6}$ Este realinhamento econômico e político global foi registrado mais claramente na Teoria Crítica de Horkheimer em sua adoção da tese do capitalismo de Estado de seu amigo Friedrich Pollock, o que teve implicações de longo alcance para o trabalho teórico e empírico do Instituto nas décadas seguintes. ${ }^{7}$ Enquanto a Teoria Crítica de Horkheimer nos anos 1930 havia se apoiado firmemente em uma teoria marxista crítica e não dogmática da transformação histórica da sociedade burguesa moderna, a tese de Pollock do capitalismo de Estado implicava que a crítica da economia política de Marx não era mais tão importante, uma vez que a dinâmica independente do capitalismo fora colocada sob controle por Estados relativamente autônomos. A dominação social era agora exercida diretamente através da política, e não mais indiretamente através de relações econômicas subjacentes. Outros sintomas da mudança de paradigma na Teoria Crítica incluíam a theory of rackets $^{8}$ e da sociedade administrada, que Horkheimer e Adorno apresentaram na Dialética do Esclarecimento. Estas categorias teóricas refletiam a nova hegemonia do modelo de capitalismo fordista-keynesiano que se desenvolveu nos Estados Unidos nos anos 1930 e 1940 e se consolidou na Europa Ocidental após a Segunda Guerra Mundial. Observando hoje, de nossa perspectiva privilegiada, podemos notar que este período do capitalismo do século XX, que perdurou até o final da década de 1960 na Europa e nos Estados Unidos, foi uma anomalia. Historiadores e economistas como Eric Hobsbawm e Thomas Piketty descreveram-no como uma "Era de Ouro", devido ao crescimento historicamente sem precedentes do capitalismo e à redistribuição

\footnotetext{
6 Para uma descrição clássica dessa mudança, veja-se Polanyi, 1944.

7 Para uma discussão da mudança na Teoria Crítica de Horkheimer ocorrida por volta de 1940 como resultado da adoção da tese de Pollock do capitalismo de Estado, veja-se Moishe Postone e Barbara Brick, "Critical Theory and Political Economy" (cf. Postone and Brick, 1993, pp.215-256); ver também, para uma interpretação relativamente diferente desta mudança, meu próprio trabalho, Max Horkheimer and the Foundations of the Frankfurt School (Abromeit, 2011, pp.394-424).

8 Nota da tradutora: A palavra "racket" provém do vocabulário inglês estadunidense e serve para designar associações criminosas, especialmente as mafiosas. Em seu uso por Horkheimer, designa a estrutura da disputa de grupos por poder político e um certo padrão de comportamento que estaria se disseminando - contexto em que a dominação política se caracterizava como dominação direta pela força. Suas origens remontam às discussões que deram origem à Dialética do esclarecimento, publicadas nas obras completas de Horkheimer, volume 12. Para mais detalhes, cf. o posfácio de Schmid Noerr à edição em inglês da Dialética do esclarecimento (Noerr, S. (2002). "Editor's Afterward". In: Horkheimer, M. and Adorno, T. Dialectic of Enlightenment. California: Stanford University Press, pp.233-236) e o capítulo "The Theory of Rackets" (em Stirk, P. (1992). Max Horkheimer: A New Interpretation. Lanham, MD: Barnes \& Noble Books, pp.131-155).
} 
da riqueza para baixo durante esse período (Hobsbawm, 1994, pp.257-288; Piketty, 2014, pp.20-27, 271-303). A hegemonia de modelos econômicos keynesianos e a ampla aceitação de um robusto estado de bem-estar social também criaram um clima histórico desfavorável para os movimentos populistas de direita na Europa e nos Estados Unidos, com poucas exceções, tais como o macarthismo nos Estados Unidos e o movimento Poujadist na França.

Dito isto, quando o Instituto estava conduzindo seus principais estudos empíricos sobre o antissemitismo, o preconceito e o autoritarismo nos Estados Unidos na década de 1940, estavam ainda muito preocupados com a questão: "poderia isso acontecer aqui?". ${ }^{9}$ O fato de o Instituto ter atribuído tanta importância a essa questão demonstra mais uma vez a convicção de que o autoritarismo populista de direita não era meramente uma patologia da cultura ou do atraso alemães, mas uma ameaça potencial em todas as sociedades capitalistas avançadas, que poderia se tornar mais poderosa no futuro, caso as condições objetivas se modificassem. Em seu prefácio de 1949 a Prophets of Deceit, de Lowenthal e Guterman, Horkheimer justifica o estudo das técnicas dos agitadores autoritários da seguinte forma:

Os incitadores de ódio [hatemongers] americanos têm, no presente, pouca influência e prestígio (...) Mas uma vez que a ênfase deste livro é sobre o significado dos fenômenos sob análise, o agitador deveria ser estudado à luz de sua efetividade potencial no contexto da sociedade atual e sua dinâmica, ao invés de em termos de sua efetividade imediata (Horkheimer, 1949, p.xii, grifos meus).

Em suma, ainda que as condições objetivas para movimentos sociais autoritários fossem desfavoráveis nos EUA nos anos 1940, Horkheimer e seus colegas do Instituto dedicaram considerável energia e recursos para estudá-los. Prophets of Deceit é um excelente exemplo disso. No prefácio do estudo, Lowenthal e Guterman reconhecem explicitamente a sua dívida teórica para com a análise de Horkheimer das dinâmicas sociais e sociopsicológicas de movimentos de massa precedentes (Lowenthal e Guterman, 1949, p.xvi). Através de uma análise do conteúdo dos discursos e escritos de agitadores populistas de direita americanos das décadas de 1930 e 1940, Lowenthal e Guterman buscaram desvendar as dinâmicas inconscientes em curso na relação entre líderes e seguidores nos movimentos autoritários. Foram identificados aproximadamente vinte temas recorrentes nos textos dos agitadores. Muitos deles permaneceram consideravelmente relevantes para análise dos movimentos populistas de direita na Europa e nos EUA até o presente. A seguir, enfatizo apenas os temas diretamente relevantes para os movimentos populistas de direita nos EUA, que se iniciaram com o Tea Party e prosseguem atualmente sob a liderança de Donald Trump - ambos serão discutidos na seção subsequente.

9 Como Eva-Maria Ziege aponta em seu Antisemitismus und Gesellschaftstheorie: Die Frankfurter Schule im amerikanischen Exil - Ziege, 2009, pp.169-171. 
Lowenthal e Guterman enfatizam que, em contraste com os movimentos fascistas europeus, o agitador autoritário americano não tem uma tradição democrática pré-liberal à qual recorrer, e, no entanto, esta ausência "não o impede de transmitir os princípios sociais essenciais do totalitarismo para a sua audiência" (Lowenthal e Guterman, 1949, p.135). Eles escrevem: “o agitador americano recai em clichês sobre patriotismo profissional, americanismo estilo quatro de julho" (idem, p.106):

Tudo o que ele pode oferecer é uma retomada do quadro institucional e ideológico estabelecido da república americana, tal como tem persistido desde os pais fundadores. (...) Se algo deu errado, só pode ser porque nós americanos (...) nos desviamos de costumes americanos (idem, p.96).

O agitador apela a "individualistas que ainda acreditam nos governos constitucionais e no american way of life" (idem, p.108). O anti-intelectualismo populista também aparece de modo proeminente em seu arsenal retórico. Eles escrevem: “tomando o tema do 'povo simples' como pretexto para adotar uma atitude agressivamente antiintelectual, o agitador descreve seus americanos como um povo de instintos bons e, ele gosta de dizer, de pouca sofisticação" (idem, p.109). Apesar destes apelos à tradição conservadora e às pessoas comuns, o agitador é hostil aos políticos e ao governo, especialmente a Franklin Delano Roosevelt e ao New Deal. Ele está “assombrado com a falta de coragem exibida na América por seus principais executivos e gerentes de negócios em resistir a agressões de burocratas políticos e revolucionários em Washington" (citado em: idem, p.48). Lowenthal e Guterman continuam: "tais afirmações aparentemente triviais servem para glorificar o domínio direto de grupos de poder econômico às expensas do governo representativo" (idem, ibidem). Ainda que o agitador seja hostil ao governo, ele "invariavelmente se identifica com as forças da lei e da ordem, e especialmente com a polícia” (idem, p.100)

Em sua contribuição para A personalidade autoritária, Adorno aborda muitos desses temas, especialmente na discussão do conceito de pseudoconservadorismo, sua tentativa mais direta de descrever as opiniões e estruturas de caráter típicos daqueles que eram mais atraídos pelos movimentos sociais populistas autoritários nos EUA. Em contraste com o conservador genuíno, que está disposto a defender instituições democráticas básicas tais como os direitos da minoria e o governo representativo, o pseudoconservador "é um homem que, em nome da manutenção de valores e instituições americanos tradicionais e da defesa deles contra perigos mais ou menos fictícios, visa consciente ou inconscientemente à sua abolição" (Adorno, FrenkelBrunswik, Levinson, Sanford, 1950, p.676). A suspeita dos pseudoconservadores em relação às instituições democráticas existentes se baseia no que Adorno chama de um "complexo de usurpação", que é a ideia de que essas instituições foram tomadas por forças hostis aos "americanos genuínos”. Nos anos 1940, tal virulência 
pseudoconservadora era frequentemente dirigida contra Roosevelt, que era visto ao mesmo tempo como um socialista e um elitista esnobe. Roosevelt e outros progressistas são considerados usurpadores porque "assumem uma posição de poder que deveria ser reservada para as 'pessoas certas' (...) governantes legítimos são aqueles que estão verdadeiramente no comando da maquinaria de produção - e não aqueles que devem seu poder efêmero a processos políticos formais" (idem, ibidem). Adorno argumenta que "a mentalidade pseudoconservadora se esforça em estabelecer - difusa e semiconscientemente - uma ditadura do grupo mais forte economicamente. Isto deve ser alcançado por meio de um movimento de massas, que promete segurança e privilégios ao assim chamado 'pequeno homem'” (idem, p.685). A profunda desconfiança dos pseudoconservadores em relação ao governo e aos políticos como um todo se alia a uma falta de empatia para com os pobres e à rejeição aos programas de bem-estar social. Partidários do "individualismo econômico severo", os pseudoconservadores fazem objeções à interferência estatal nas leis "naturais" do mercado e adotam o espírito do adágio "aqueles que não trabalham, não devem comer". Este desprezo pelos pobres como parasitas vem geralmente acompanhado da admiração pelos ricos e bem-sucedidos como sendo supostamente os membros mais produtivos da sociedade.

Esta ideologia de produtores e parasitas também reaparece no estudo do Instituto sobre o antissemitismo entre trabalhadores americanos nos anos $1940 .{ }^{10} \mathrm{O}$ estudo revelou que, ao se comparar os Estados Unidos à Europa, o antissemitismo não só era mais disseminado entre os trabalhadores do que entre a classe média, como também assumia formas mais "modernas". Em outras palavras, os trabalhadores americanos estavam em grande medida isentos das formas mais vulgares e grosseiramente conspiratórias de antissemitismo europeu, que retratavam os judeus como predadores lascivos e/ou violentos. As formas de antissemitismo disseminadas entre os trabalhadores americanos quase sempre envolviam questões econômicas e a crença de que os judeus tentavam evitar o trabalho manual a qualquer custo; que através de logro e manipulação, eles sobreviviam como parasitas e exploradores entre a maioria de gentios virtuosos, que trabalhavam duro. Curiosamente, esta forma de antissemitismo entre trabalhadores americanos correspondia mais estreitamente ao que Horkheimer e Adorno descreveram na Dialética do esclarecimento como antissemitismo "burguês". 0 antissemitismo burguês baseava-se em uma distinção ideológica entre os "schaffend" e os "raffend". Os primeiros, os produtores virtuosos, incluem não apenas trabalhadores e camponeses, mas também a manufatura e a grande indústria. Os últimos, os parasitas imorais, incluem burocratas, políticos, comerciantes e especialmente banqueiros. Baseando-se na crítica de Marx e Engels

10 Para uma discussão mais detalhada acerca do estudo do Instituto sobre antissemitismo entre os trabalhadores americanos, ver Worrell, 2008 e Ziege, 2009, pp.180-228. 
a Proudhon, em Eugen Dühring e nas formas de antissemitismo populista no século XIX à esquerda e à direita, Horkheimer e Adorno salientam que o antissemitismo burguês se apoia no encobrimento da dominação social na propriedade dos meios de produção. Enquanto Marx e Engels se concentraram na exploração do trabalho assalariado pelo capital, o antissemitismo populista e o fascismo retratam os trabalhadores assalariados e o capital como aliados produtivos na luta contra políticos e banqueiros parasitários. O fato de essas formas burguesas de antissemitismo serem tão difundidas entre os trabalhadores americanos aponta para o que Adorno descreveria posteriormente como o caráter "radicalmente burguês" da sociedade americana como um todo; ou seja, para o fato de que a consciência socialista que na Europa também incluíra uma crítica do antissemitismo como o "socialismo dos tolos" - era praticamente inexistente entre os trabalhadores americanos. ${ }^{11} 0$ antissemitismo destes era um protesto distorcido contra a exploração capitalista do trabalho, mas que se baseava em uma completa identificação dos trabalhadores com os valores burgueses do trabalho árduo e da autodisciplina (cf. Worrel, 2008, pp.119188).

Antes de seguir com algumas observações sobre como o Tea Party e Donald Trump exemplificam muitas das características dos movimentos populistas de direita identificados por Horkheimer, Adorno e Lowenthal, gostaria de retornar às reflexões anteriores sobre como o desenvolvimento da Teoria Crítica da Escola de Frankfurt se enquadra na história do século XX. Mencionei anteriormente que a ascensão de formas de capitalismo centradas no Estado na metade do século XX criou condições desfavoráveis aos movimentos sociais autoritários nos Estados Unidos e na Europa Ocidental. Nos anos 1970, houve uma transição do modelo de capitalismo fordistakeynesiano, dos anos 1950 e 1960, para uma nova fase pós-fordista e neoliberal, que perdurou até o presente. Ainda que apenas brevemente, gostaria de apresentar a tese de que estas condições sociais modificadas criaram um clima que, em alguns aspectos, se assemelha mais àquele dos anos 1920 e 1930 e que é mais propício aos movimentos populistas de direita na Europa e nos Estados Unidos. Após um período de transição nos anos 1970, a nova hegemonia das ideias neoliberais foi marcada pela eleição de Ronald Reagan e de Margaret Thatcher, mas também por Helmut Kohl e o conservador "Tendenzwende" na Alemanha Ocidental do início dos anos 1980. Em todos os três casos, algumas ideias chave populistas de direita foram adotadas e colocadas em prática - ainda que em uma forma mais moderada - por partidos

11 Adorno se referiu aos Estados Unidos como um "país radicalmente burguês" em seu ensaio "Über Tradition" (cf. Adorno, 1977, p.310). Para um exame do papel muito mais significativo que o racismo desempenhou na formação de identidades "brancas" entre a classe trabalhadora dos Estados Unidos - identidades que também tinham características decididamente burguesas -, ver "Whiteness as a Form of Bourgeois Anthropology? Historical Materialism and Psychoanalysis in the Work of David Roediger, Max Horkheimer, Erich Fromm, and Herbert Marcuse" (Abromeit, 2013, pp.325-343). 
conservadores recém dominantes. Mesmo na França, François Mitterand foi forçado a abandonar suas ambiciosas promessas de campanha de reformas econômicas socialistas e a adotar políticas muito mais amigáveis ao empresariado no início dos anos 1980. A França oferece um exemplo particularmente claro não só da derrota de ideias socialistas tradicionais, mas também do surgimento de novos movimentos políticos populistas de direita e autoritários nos anos 1980. Ao mesmo tempo em que o partido socialista francês fazia sérias concessões à nova ortodoxia neoliberal e o partido comunista francês entrava em um período de declínio terminal, a Front Nationale populista de direita surgia como uma nova força na política eleitoral francesa. Como apontou o cientista político holandês Cas Mudde, a Frente Nacional era apenas um caso de toda uma nova família de movimentos e partidos populistas de direita que iriam surgir na Europa nos anos 1980 e 1990 (cf. Mudde, 2016, pp.295307). O colapso do comunismo soviético em 1989 só reforçou a hegemonia agora triunfalista do neoliberalismo e do "Consenso de Washington". Bill Clinton e Tony Blair deixaram claro que os "novos" democratas e o "novo" trabalhismo haviam adotado plenamente ideais neoliberais. Quando questionada em 2002 sobre qual era o seu maior feito, Thatcher respondeu: "Tony Blair e o novo trabalhismo".

$\mathrm{O}$ argumento mais amplo que pretendo defender aqui - sucintamente - é que os anos 1980 e 1990 foram marcados por um significativo deslocamento à direita no espectro político geral, tanto na Europa como nos Estados Unidos. A adoção do neoliberalismo por socialistas, democratas e socialdemocratas; níveis crescentes de desigualdade e desemprego; e a ameaça de novas crises capitalistas, tal como a ocorrida em 2008, criaram um solo fértil para a emergência de novos movimentos populistas de direita. Certamente as instituições e tradições democráticas são muito mais fortes na Europa hoje do que eram nos anos 1920 e 1930 e mesmo os novos partidos populistas de direita aceitam as precondições da democracia, em vez de se oporem a elas. No entanto, três décadas e meia de hegemonia neoliberal criaram condições - níveis crescentes de pobreza, insegurança, desesperança - que mais se assemelham aos anos 1920 e 1930 do que aos anos 1950 e 1960. Por esta razão, penso que é válido também revisitar o que denominei anteriormente de modelo da primeira Teoria Crítica, que guiou o trabalho do Instituto nos anos 1930 e explorou a relação entre a crise capitalista e os movimentos sociais autoritários. 0 ensaio de Horkheimer “Egoísmo e movimentos de libertação” é - como mencionado - paradigmático a este respeito, mas os escritos de Fromm dos anos 1930 sobre as dinâmicas sociopsicológicas do autoritarismo, estreitamente relacionados a ele, também devem ser mencionados neste contexto. ${ }^{12}$ Em contraste com o período pós Segunda Guerra Mundial, quando condições sociais e econômicas não eram propícias ao surgimento de movimentos

12 Para uma visão geral dos escritos de Fromm dos anos 1930 sobre as dimensões sociopsicológicas do autoritarismo, ver Abromeit, 2011, pp.201-211, 282-288. 
autoritários, os escritos de Horkheimer e Fromm dos anos 1930 são embasados em observações diretas dos vínculos entre as crises capitalistas e o populismo de direita e, portanto, devem ser revisitados à luz do recente ressurgimento de crises e do autoritarismo nos Estados Unidos e na Europa.

\section{O ressurgimento do populismo de direita nos Estados Unidos: o Tea Party e Donald Trump}

Nesta seção, gostaria de analisar com mais detalhe o movimento Tea Party nos Estados Unidos. O Tea Party irrompeu na cena política estadunidense na primavera de 2009, em resposta à eleição de Barack Obama e à crise econômica de 2008. A convocação original para as reuniões do Tea Party veio de um repórter em Chicago chamado Rick Santelli, que se revoltou em face da intenção declarada pelo recémeleito presidente Obama de ajudar pessoas ameaçadas de perder suas casas como resultado da crise de empréstimos do subprime. Em sua preleção, que logo se tornou viral no You Tube, Santelli acusou o governo de "recompensar o mau comportamento" e convocou os "capitalistas americanos" a protestarem contra medidas para "subsidiar hipotecas de fracassados" (citado em Skocopl \& Williams, 2012, p.7). O Tea Party logo tornou-se uma das maiores irrupções de ativismo político de base nos Estados Unidos desde os anos 1960. Este ativismo de base, combinado com o generoso apoio de organizações políticas nacionais abastadas e ultraconservadoras e de poderosos meios de comunicação conservadores, como Fox News, fez do Tea Party uma nova força política a ser considerada. No auge de sua influência política, nas eleições de meio de mandato, em novembro de 2010, o Tea Party contribuiu significantemente para uma vitória esmagadora dos republicanos. Os republicanos conquistaram 63 assentos na Câmara dos Representantes, seis assentos no Senado, seis novos cargos de governadores e tiveram ganhos igualmente impressionantes nas legislaturas estaduais por todo o país. Muitos dos candidatos vitoriosos apoiados pelo Tea Party haviam derrotado republicanos mais moderados nas eleições primárias. O efeito geral foi de deslocar a política nacional significantemente à direita. ${ }^{13}$ Pesquisas realizadas em 2010 e 2011 demonstraram repetidamente que aproximadamente 30\% dos americanos "apoiavam" e 20\% "apoiavam fortemente" o Tea Party. Embora não tenham conseguido evitar a reeleição de Barack Obama em 2012, desempenharam um papel importante nas amplas conquistas dos republicanos nas eleições intermediárias de 2014. Em seu recente estudo, The Tea Party and the Remaking of Republican Conservatism, Theda Skocpol e Vanessa Williamson,

13 Adam Bonica, cientista político de Stanford, afirmou que a Câmara dos Representantes teve sua mais pronunciada mudança ideológica à direita como resultado das eleições de 2010 - ainda mais radical do que a assim chamada "revolução republicana" liderada por Newt Gingrich em 1994. Cf. Skocopl \& Williams, 2012, pp.168-170. 
socióloga e cientista política de Harvard, afirmam que o Tea Party teve sucesso em revitalizar o Partido Republicano, que até recentemente, em 2009, parecia ser um partido em declínio. No processo, o Tea Party também teve sucesso em impelir o Partido Republicano para a direita em muitos temas; pode-se dizer, empregandose a distinção de Adorno acima mencionada, que os pseudoconservadores do Tea Party tiveram sucesso em fortalecer sua posição face aos conservadores tradicionais dentro do Partido Republicano.

Opondo-se a alguns comentadores que viram o Tea Party como uma nova força independente na política americana, Skocpol e Williamson argumentam de modo convincente que ele representa "a mais recente encarnação do populismo conservador americano" (Skocopl \& Williams, 2012, p.81). Portanto, quando se estuda o Tea Party mais detidamente, não deve surpreender que exista um grau de correlação extremamente alto entre as suas crenças unificadoras e as principais características dos agitadores populistas de direita e das personalidades autoritárias que Horkheimer, Adorno e Lowenthal estudaram nos Estados Unidos nos anos 1940. Estes incluem o "Patriotismo estilo quatro de julho" exacerbado e frequentes apelos aos pais fundadores e a um retorno ao governo baseado diretamente na Constituição dos Estados Unidos, que é interpretada dogmaticamente como se embasasse a doutrina do Tea Party. Um livro bastante popular no Tea Party, chamado The Five Thousand Year Leap, pretende explicar as articulações entre a Bíblia e a Constituição dos Estados Unidos. ${ }^{14}$ Tal fundamentalismo histórico também ilustra a crença disseminada no Tea Party de que o Estados Unidos foi corrompido por elementos estrangeiros e precisa purgar-se para retornar ao seu estado anterior puro - o que Adorno denominou de "o complexo de usurpação". Tais elementos estrangeiros incluem os imigrantes sem documentação, que $82 \%$ dos membros do Tea Party veem como um problema "muito grave". Muito mais grave, no entanto, aos olhos de quase todos os membros do Tea Party, era o próprio presidente Obama. Não é coincidência que o Tea Party tenha surgido pouco após a sua eleição. Não muito diferente dos agitadores de Lowenthal e das personalidades autoritárias de Adorno, que viam Franklin Delano Roosevelt ao mesmo tempo como um comunista e um elitista esnobe, os membros do Tea Party veem Obama como um socialista e um elitista condescendente, mas também como um estrangeiro e um muçulmano. Skocpol e Williamson enfatizam a centralidade da visão de Obama como "o diabo encarnado" para o Tea Party e da "paranoia antiObama” [free-wheeling anti-Obama paranoia] como traço comum. O ódio a Obama é também alimentado pela desconfiança mais generalizada do Tea Party em relação ao governo, fundamentada em suas concepções econômicas ultraliberais e darwinistas sociais: deve-se permitir que as leis "naturais" do mercado sigam seu curso e o

14 Sobre a interpretação bastante seletiva e tendencialmente fundamentalista da Constituição dos Estados Unidos pelo Tea Party, ver Lepore, 2010, especialmente pp.118-125. 
governo não deveria intervir para ajudar os pobres. O Tea Party é anti-sindical e pró-negócios pela mesma razão. Eles não fazem distinção entre negócios de pequeno porte e grandes corporações e se opõem ao aumento de impostos sobre qualquer um, inclusive sobre os americanos mais ricos. Algumas exceções interessantes a suas visões geralmente antigovernamentais incluem uma falta de incômodo em relação a grandes orçamentos militares, uma posição pró-polícia e pró-militar, e a convicção de que é necessário um controle mais rigoroso de imigrantes sem documentação. Aqui vemos a mesma atitude antigovernamental e pró-polícia que Adorno descreveu em A personalidade autoritária e também vinculou à ascensão do fascismo na Europa.

Gostaria de me deter um pouco mais na outra exceção às concepções antigovernamentais do Tea Party, pois ela representa uma das descobertas mais interessantes de Skocpol e Williamson. Eles constataram que a maioria dos membros de base do Tea Party apoiam certos programas governamentais, tais como a Previdência Social e o Medicare, que consideram como auxílio aos cidadãos americanos “merecedores”. Algumas das organizações nacionais libertárias de extrema direita que apoiaram e financiaram grupos locais do Tea Party defendem a privatização da Previdência Social e do Medicare. Mas estas concepções seguem impopulares entre os membros de base, cujo sentimento de que há membros da sociedade merecedores e não merecedores é ainda mais forte do que sua oposição ao governo. Skocpol e Williamson escrevem:

Acima de tudo, os ativistas do Tea Party veem a si mesmos como membros produtivos da sociedade. (...) Uma distinção bem marcada entre trabalhadores e não trabalhadores - entre cidadãos produtivos e parasitas - é central à visão de mundo e concepção da América do Tea Party. (...) Para o Tea Party, apenas através do trabalho árduo podese merecer acesso a uma boa renda e a benefícios públicos honrosos (Skocopl, \& Williams, 2012, pp.65-66)..$^{15}$

Aqui, penso que podemos perceber outra articulação importante com as formas anteriores do populismo de direita analisadas por Horkheimer, Adorno e Lowenthal, isto é, a ideologia dos produtores e parasitas. ${ }^{16}$ Vimos como esta ideologia figurava de modo proeminente não apenas entre os agitadores populistas de direita e personalidades autoritárias, mas também entre os trabalhadores americanos antissemitas. Vimos também esta ideologia na distinção feita pelos nazistas entre os "schaffend" e os "raffend". A análise de Horkheimer, em "Egoísmo e movimentos de libertação", da formação histórica de estruturas de caráter dominantes na época burguesa moderna ainda pode nos oferecer insights importantes sobre as origens e a função da ideologia de produtores e parasitas. Estamos lidando aqui com uma atitude

15 Estas convicções também podem ser observadas nos comícios do Tea Party, em que os participantes carregam cartazes dizendo "Redistribua a minha ética de trabalho" ou "Siga trabalhando; milhares em assistência social dependem de você".

16 Sobre a importância da ideologia de "produtores e parasitas" para o Tea Party, veja-se também The Tea Party: A Brief History - Formisano, 2012, p.20. 
que se difundiu primeiro entre a burguesia ascendente, mas que foi gradualmente imposta também sobre as classes mais baixas, durante o longo e moroso processo de sua integração à sociedade capitalista moderna. ${ }^{17} \mathrm{~A}$ ideologia dos produtores e parasitas foi utilizada durante a Revolução Francesa para justificar uma revolta contra a aristocracia e foi apropriada no século XIX por alguns socialistas não marxistas para atacar a burguesia. Mas também foi facilmente integrada ao arsenal ideológico dos fascistas. ${ }^{18}$ Este deslocamento da ideologia de "produtores e parasitas" é um ótimo exemplo da transformação do populismo da esquerda para a direita, discutido no início deste trabalho em relação ao ensaio de Horkheimer "Egoísmo e movimentos de libertação".

Mais recentemente, Donald Trump conseguiu mobilizar e expandir o movimento populista de direita, que explodiu na cena política com o Tea Party. ${ }^{19}$ A fim de compreender o extraordinário sucesso político de Trump - apesar da oposição da maior parte das lideranças tradicionais do partido - é preciso olhar atentamente para algumas das semelhanças e diferenças entre a sua retórica e aquela do Tea Party. Em muitos aspectos, Trump continuou a enfatizar elementos chave da ideologia do Tea Party. Estes incluem, por exemplo o ataque virulento e frequentemente conspiratório ao Presidente Obama; ${ }^{20}$ a celebração da polícia e dos direitos às armas da Segunda Emenda, combinados a mordazes ataques ao governo atual e ao governo em geral; os clamores hiper-patrióticos para se restaurar os EUA a um estado de grandeza passada nostalgicamente imaginado; e mordazes ataques aos imigrantes. Quando ao último ponto, Trump foi - como se sabe - bem além do Tea Party em seu clamor pela deportação imediata de mais de dez milhões de trabalhadores sem documentação, pela revogação da cidadania de seus filhos nascidos nos EUA e pela construção de um muro ao longo da fronteira mexicana, que evitará qualquer futura imigração e será alegadamente financiado pelo governo mexicano. A afirmação de Trump de que muitos imigrantes mexicanos são assassinos e estupradores, combinada ao seu reforço da popular e preconceituosa associação de muçulmanos com terroristas e à sua ameaça de limitar rigorosamente a imigração muçulmana para os EUA, demonstraram a sua

17 Para uma análise de como este processo foi diferente nos Estados Unidos e na Europa, devido à presença de uma grande subclasse negra, veja-se meu ensaio "Whiteness as a Form of Bourgeois Anthropology?", citado acima, na nota 11.

18 Para uma análise mais detalhada da transformação da ideologia populista de "produtores e parasitas" da esquerda para a direita na Europa do período da Revolução Francesa até o fascismo, veja-se meu ensaio "Transformations of Producerist Populism", citado acima, na nota 3.

19 A seguinte análise de Trump coloca foco sobre as estratégias retóricas desenvolvidas por ele durante sua campanha. Uma análise das formas pelas quais Trump tem - dede que venceu a eleição - se distanciado de algumas das mais extravagantes dessas asserções não pode ser feita aqui, uma vez que este processo está ainda em curso no momento da escrita deste artigo.

20 Donald Trump foi um dos primeiros a questionar a cidadania de Obama e participou ativamente do assim chamado movimento "birther". 
disposição em superar até mesmo o Tea Party em excessos retóricos xenófobos. ${ }^{21}$ Outra área chave em que Trump adotou e ampliou a retórica do Tea Party é em relação ao que Adorno denominou o “complexo de usurpação”. Como o Tea Party, Trump sugere constantemente que o governo foi tomado por interesses especiais (por exemplo, políticos em débito para com os lobistas) e precisa ser "tomado de volta" de modo a servir ao povo adequadamente. Trump enfatiza seu estatuto de outsider, que financiou sua própria campanha, ao invés de aceitar dinheiro corruptor de grupos de interesse especiais estabelecidos, e que concorre à presidência apenas porque está "farto" do "sistema desonesto" que está destruindo a democracia americana e impedindo a expressão da vontade do povo. ${ }^{22}$ Trump assegura repetidamente a sua audiência de que "a última coisa que eu imaginei que faria é tornar-me um político". Mas, em palavras que poderiam ter sido retiradas textualmente de uma série de agitadores protofascistas estudados por Lowenthal nos anos 1940, Trump explica à sua audiência que decidiu relutantemente entrar na política porque os EUA precisam colocar sua casa em ordem e que ele é o homem perfeito para esse trabalho. Ele insiste que suas realizações como homem de negócios abastado, incorporador imobiliário bem-sucedido e negociador firme são as qualificações ideais para "tornar a América grandiosa novamente”. Aqui se vê, ainda mais claramente do que no Tea Party, o apelo de Trump àqueles que acreditam que o governo deveria ser conduzido como uma empresa e que o poder político deveria ser colocado nas mãos “[d]aqueles que estão no comando da maquinaria de produção - e não [d]aqueles que devem seu poder efêmero a processos políticos formais", como Adorno descreveu a atitude pseudoconservadora em relação ao governo. ${ }^{23}$

Trump também adotou a retórica de "produtores e parasitas" que desempenha papel central na ideologia do Tea Party. De fato, em um discurso pronunciado na convenção do Tea Party da Carolina do Sul em 16 de janeiro de 2016, ele dedicou quase metade de seu tempo para descrever um projeto de construção de um ringue de patinação no gelo que assumiu do governo da cidade de Nova York, pois estava atrasado e acima do orçado, e se vangloriou de como, sob sua direção, o projeto foi concluído antes do previsto e abaixo do orçamento, contrastando assim a sua própria eficiência produtiva com a dispendiosa incompetência do governo. ${ }^{24}$ Trump

21 Sobre a disposição de Trump em violar tabus mantidos pelos conservadores tradicionais, veja-se o artigo seguinte de Rick Perlstein, célebre historiador dos movimentos políticos conservadores contemporâneo nos Estados Unidos: http://washingtonspectator.org/donald-trump-and-thef-word (acessado em 03.01.2016). Perlstein afirma que "Donald Trump é o primeiro candidato presidencial republicano a aventurar-se com uma demagogia tão pura".

22 Ver, por exemplo, o discurso que Trump pronunciou em Rochester, Nova York, em 10 de abril de 2016, que pode ser encontrado aqui: https://www.youtube.com/watch?v=NqRMaD3HWHo (acessado em 03.01.2016).

23 Citado acima - Adorno, Frenkel-Brunswik, Levinson, Sanford, 1950, p.676.

240 discurso de Trump pode ser encontrado aqui: https://www.youtube.com/watch?v=n-zN5k4Gu40 (acessado em 03.01.2016). 
sempre descreve sua própria atividade profissional de incorporador imobiliário como contribuindo diretamente para a produtividade dos Estados Unidos ao empregar diretamente milhares de pessoas. Provavelmente, a maneira mais importante pela qual Trump se diferenciou de outros candidatos republicanos - particularmente daqueles do establishment do partido - foi sua adoção do populismo econômico e do protecionismo. Ele promete tornar a América poderosa novamente ao trazer de volta as centenas de milhares de empregos fabris que desapareceram dos EUA desde os anos 1970 como resultado de acordos comerciais como o NAFTA, que beneficiaram grandes corporações às custas dos trabalhadores americanos. Trump promete punir corporações que optem por produzir no exterior, ao cobrar tarifas pesadas sobre seus produtos. Ele vocifera contra o governo e as elites corporativas que se esqueceram dos trabalhadores assalariados ou são contra eles. ${ }^{25}$ Ele prometeu até mesmo transformar o Partido Republicano em um partido de trabalhadores. ${ }^{26}$ Enquanto muitos comentadores argumentaram que o racismo e a xenofobia de Trump são aquilo que tem mais apelo entre seus eleitores, outros experientes estudiosos do populismo de direita americano veem seu populismo econômico como mais importante. ${ }^{27} \mathrm{~A}$ ideologia dos produtores e parasitas é também aparente nas frequentes críticas de Trump às finanças - na forma de gestores de fundos - e aos bancos. Trump criticou reiteradamente seu mais importante rival nas primárias republicanas, Ted Cruz, por sua disposição em aceitar dinheiro de grandes bancos de Wall Street. ${ }^{28}$ Em contraste com Cruz e os demais candidatos nas primárias republicanas, Trump nunca deixa sua audiência esquecer de que ele está financiando sua campanha com dinheiro próprio. Ele estende a retórica dos produtores e parasitas até mesmo para relações internacionais militares e comerciais. Uma das primeiras coisas que alegou que faria quando se tornasse presidente é forçar países como Alemanha, Japão e Arábia Saudita, que supostamente dependem da generosidade dos EUA para sua defesa militar, a pagar por esse serviço ou a providenciar sua própria defesa. De modo similar, no comércio internacional, Trump alude recorrentemente ao México e à China, em particular, por estarem enganando o atual ingênuo e/ou inepto governo americano e tirando vantagem do povo americano ao obter grandes superávits primários.

A última, mas provavelmente mais importante, forma pela qual Trump adotou e intensificou a retórica do Tea Party reside no conjunto de ideias - acima

25 No discurso que Trump pronunciou em Rochester em abril de 2016, citado na nota 22.

26 Conforme relatado na revista online Politico, em 26 de maio de 2016: http://www.politico.com/ story/2016/05/trump-gop-workers-party-223598 (acessado em 03.01.2016).

27 Para um argumento que enfatiza o populismo econômico de Trump, veja-se Thomas Frank, "Millions of ordinary Americans support Donald Trump. Here's Why". The Guardian, (7 de março de 2016): https://www.theguardian.com/commentisfree/2016/mar/07/donald-trump-why-americanssupport (acessado em 03.01.2016).

28 Neste ponto, é inequívoco o eco populista de direita das críticas populistas de esquerda de Bernie Sanders a Hillary Clinton. 
discutidas - a que Adorno se refere como "pseudoconservadorismo". Para vincular explicitamente o conceito chave de pseudoconservadorismo em Personalidade autoritária às análises anteriores de Horkheimer das tendências autoritárias entre os movimentos de libertação burgueses no início do período moderno, vale recordar que Adorno vê o pseudoconservadorismo como uma tendência histórica profunda, que acompanhou a ascensão do capitalismo moderno como um todo, mas cuja expressão é dificultada ou facilitada pelas condições sociais e políticas que existem em diferentes períodos da época burguesa moderna. ${ }^{29}$ Para compreender o recente sucesso do Tea Party e de Trump, também vale recordar a razão pela qual Adorno distinguiu "pseudoconservadores" de conservadores genuínos, a saber, para contrastar as tendências autoritárias dos primeiros com a identificação mais ou menos bem sucedida dos últimos com os ideais da democracia liberal. De acordo com Adorno, uma característica definidora crucial da aceitação por parte dos conservadores genuínos dos aspectos "antirrepressivos e sinceramente democráticos" dos ideais políticos dos Estados Unidos é uma “rejeição absoluta do preconceito antiminorias" (Adorno, Frenkel-Brunswik, Levinson, Sanford, 1950, p.675). A previsão de Adorno de que "os conservadores 'genuínos' serão levados para o campo liberal pela dinâmica social do presente" parece ter sido confirmada pelas profundas divisões que surgiram no Partido Republicano na década passada, primeiro com o Tea Party e agora - em uma medida ainda maior - com a rebelião aberta de Trump contra as elites tradicionais conservadoras do partido. ${ }^{30}$ Mas agora que a rebelião pseudoconservadora iniciada pelo Tea Party e ampliada por Trump tomou o controle do Partido Republicano e colocou o seu líder autodeclarado na Casa Branca, vários republicanos de altoescalão, que foram bastante críticos em relação a Trump no passado - incluindo o atual porta-voz da Casa dos Representantes, Paul Ryan, e o candidato presidencial republicano de 2012, Mitt Romney, - já têm demonstrado uma maior disposição em trabalhar com Trump. ${ }^{31}$

Caso se questione como a retórica de Trump reflete o conteúdo do

29 Adorno argumenta, por exemplo, que "a razão pela qual o pseudoconservadorismo parecer ser um fenômeno tão caracteristicamente moderno não é porque qualquer novo elemento psicológico tenha sido acrescido a esta síndrome particular, que provavelmente foi estabelecida durante os últimos quatro séculos, mas porque condições sociais objetivas tornam mais fácil para a estrutura de caráter em questão se expressar em suas opiniões professadas" (Adorno, Frenkel-Brunswik, Levinson, Sanford, 1950, p. 676).

30 Antes de Trump obter a nomeação do Partido Republicado e a presidência, muitas elites poderosas do Partido Republicano, como George H.W. Bush, George W. Bush e Mitt Romney, assim como alguns dos mais abastados doadores do partido, como os irmãos Koch, se recusaram a apoiar Trump.

31 Durante as primárias de 2016, Trump criou uma espécie de teste decisivo que forçou os republicanos a se identificarem com ele, como pseudoconservedores, ou contra ele, como conservadores genuínos. Mas o fato de que a maior parte deles tem, desde então, demonstrado maior disposição em trabalhar com Trump parece colocar em dúvida o argumento de Adorno de que o compromisso das elites conservadoras com os princípios liberais democráticos os conduziriam a rejeitar os pseudoconservadores e a gravitar na direção dos liberais moderados. 
pseudoconservadorismo tal como descrito por Adorno, muitas continuidades com os pontos destacados acima em relação ao Tea Party são prontamente aparentes. Mas também se nota o que eu gostaria de defender ser a maior diferença entre Trump e o Tea Party, a saber, a retórica e a autoapresentação muito mais explicitamente autoritárias de Trump. Enquanto o Tea Party ainda se orgulhava em ser um movimento de bases e descentralizado, Trump deu um novo foco centralizado ao movimento, com sua liderança pomposa e agressiva. Adorno descreve o desejo dos pseudoconservadores por uma liderança autoritária da seguinte forma:

Sua ideia de um homem forte (...) é influenciada por uma imagem de força real; o apoio dos grupos industriais mais poderosos. Para eles, os progressistas no governo são os reais usurpadores (...) por assumirem uma posição de poder que deveria ser reservada para as "pessoas certas". Os pseudoconservadores têm um senso subjacente de "legitimidade": os governantes legítimos são aqueles que estão de fato no comando da maquinaria de produção - e não aqueles que devem seu poder efêmero a processos políticos formais (...) A democracia formal parece, a esse tipo de pensamento, muito distante do "povo" e o povo terá seus direitos apenas se os "ineficientes" processos democráticos forem substituídos por algum sistema de braço firme indefinido (Adorno, Frenkel-Brunswik, Levinson, Sanford, 1950, pp.677$78,686)$.

Embora Trump não seja um industrial - o que em si pode ser de menor significado em um período "pós-industrial" - ele certamente se apresenta como um homem de negócio produtivo e eficiente com uma compreensão íntima de "como fazer as coisas" no "mundo real" da economia e como alguém que irá aplicar estes métodos para “tornar a América grandiosa novamente". Embora haja um debate entre acadêmicos e jornalistas sobre se Trump é mais autoritário ou populista, este debate negligencia o fato de que o populismo de direita e o autoritarismo muito frequentemente andam juntos, como a experiência do fascismo europeu nos anos 1920 e 1930 deixou claro. ${ }^{32}$ Isso não significa dizer, como outros comentadores alegaram, que Trump é ele mesmo um fascista absoluto. Embora seus clamores pela deportação de mais de dez milhões de trabalhadores sem documentação e suas ameaças de usar violência contra seus inimigos e oponentes - e a tolerância disso entre seus seguidores - certamente situe bem a sua retórica dentro das tradições fascistas, e ele não invocou a derrubada das instituições políticas dos Estados Unidos e não formou seu próprio partido político anti-democrático nem milícias - embora diversos militantes de extrema direita e/ou grupos supremacistas brancos tenham expressado seu apoio a ele. ${ }^{33}$

No entanto, Trump e muitos de seus seguidores se encaixam muito bem no

32 Para um exemplo de uma crítica dos diversos artigos que analisaram Trump como um autoritário, ver Rahn and Oliver, "Trump's voters aren't authoritarians, new research says. So what are they?" Washington Post, March 9, 2016.

33 Sobre o apoio de Trump entre a extrema direita, os supremacistas brancos e os neo-nazistas nos Estados Unidos, ver Peter Holley and Sarah Larimer, "How America's dying white supremacist movement is seizing on Donald Trump's appeal”. Washington Post, February 29, 2016. 
molde do populismo de direita autoritário - ou seja, naquilo que Adorno descreveu como "pseudoconservadorismo". E, como Adorno seguiu repetindo até sua morte em 1969, a ameaça do autoritarismo nas sociedades capitalistas modernas, que vem de dentro da democracia, é provavelmente maior do que a ameaça colocada por movimentos explicitamente anti-democráticos. ${ }^{34} \mathrm{Em}$ A personalidade autoritária, Adorno descreve esta ameaça da seguinte forma:

Não se pode contestar que a democracia formal, sob o presente sistema econômico, não basta para garantir permanentemente, para a maioria da população, a satisfação dos desejos e necessidades mais elementares, enquanto ao mesmo tempo a forma democrática de governo é apresentada como se (...) fosse o mais próximo possível de uma sociedade ideal. 0 ressentimento causado por essa contradição é voltado, por aqueles que não reconhecem suas raízes econômicas, contra a forma democrática em si. Por não cumprir o que promete, eles a veem como uma "fraude" e estão prontos para trocá-la por um sistema que sacrifica todas as pretensões por dignidade humana e justiça, mas do qual esperam vagamente algum tipo de garantia de suas vidas por meio de um melhor planejamento e organização (Adorno, Frenkel-Brunswik, Levinson, Sanford, 1950, p.678).

Trump joga com este tipo de ressentimento populista e antipolítico quando afirma repetidamente em seus discursos que o sistema político atual é corrupto, mas que ele, como um indivíduo, tem os meios não apenas para reverter o lamentável declínio dos Estados Unidos, mas para fazê-lo rapidamente: "Vocês precisam de alguém rápido"; “acontecerá rápido" e "eu sozinho posso resolver este problema”, como ele disse a uma enorme audiência em um discurso em 10 de abril de 2016 em Rochester, New York - uma cidade dizimada pelo declínio pós-industrial. A mensagem de Trump de protecionismo econômico, que o diferencia de outros candidatos republicanos e da ideologia neoliberal das elites conservadoras estadunidenses em geral, é feita sob encomenda para audiências brancas e de classes baixas ou média baixas, como aquela a que ele se dirigia em Rochester. Não diferente das promessas dos nacionaissocialistas de restaurar uma poderosa Volksgemeinschaft, ${ }^{35}$ Trump diz a seus ouvintes para se unirem ao seu "movimento" para restaurar um Estados Unidos mítico no qual iremos "proteger e amar uns aos outros". Trump vocifera contra os grandes bancos e lobistas corporativos e diz à sua audiência que ele é "o único que vai salvar a previdência social". ${ }^{36}$ Aqui novamente podemos ver Trump muito perspicazmente se situando do lado dos ativistas de base do Tea Party e contra o neoliberalismo das elites conservadoras, como os irmãos Koch e Paul Ryan, que favoreceram a privatização da previdência social. Assim, Trump apropriou os elementos comunitaristas da ideologia

34 Como Adorno notoriamente afirmou em 1959, "eu considero a sobrevivência do nacional-socialismo dentro da democracia como potencialmente mais ameaçadora do que a sobrevivência de tendências fascistas contra a democracia" (Adorno, 1998, p.90).

35 Sobre a importância do conceito de Volksgemeinschaft ("comunidade do povo") para a ideologia nazista, ver Fritzsche, 1998.

36 Como Trump afirmou em seu discurso de abril de 2016 em Rochester, citado na nota 22, acima. 
do Tea Party, ao mesmo tempo os intensificando, ao combiná-los com seu próprio apelo como um líder autoritário que supostamente tem poder de acioná-los e de punir aqueles “inimigos do povo" - domésticos e estrangeiros - que são responsáveis pelo declínio dos Estados Unidos.

\section{Conclusão}

Uma razão pela qual o fascismo tem uma chance é que, em nome do progresso, os seus oponentes o tratam como uma norma histórica. $O$ espanto atual de que as coisas que estamos vivendo sejam "ainda” possíveis no século XX não é filosófica. Este espanto não é o começo do conhecimento - a não ser que seja o conhecimento de que a visão de história que o engendra é insustentável (Benjamin, 1968, p.257)

Estas palavras, que Benjamin escreveu em face do apelo ininterrupto e do avanço contínuo do fascismo na Europa no fim dos anos 1930, ainda podem esclarecer as atitudes históricas dominantes irreflexivas do século XXI que levaram a uma significativa subestimação da ameaça - e à consequente surpresa com a ascensão - do populismo de direita na Europa e nos Estados Unidos. Como vimos, Horkheimer, Fromm, Adorno e Lowenthal basearam suas análises do fascismo, do autoritarismo e do populismo de direita em uma teoria histórica da época burguesa moderna como um todo. A provocativa tese do inovador ensaio de Horkheimer, "Egoísmo e movimentos de libertação", - que forneceu as bases históricas e teóricas para boa parte do trabalho posterior do Instituto sobre o autoritarismo - era a de que as dinâmicas social e sociopsicológica específicas que conduziram ao fascismo na Europa nos anos 1920 e 1930 tinham estado presentes desde o começo da sociedade burguesa moderna. Certamente, a constelação de relações sociais entre a aristocracia, as classes médias e baixas passou por uma transformação conforme a burguesia estabelecia gradualmente sua hegemonia ao longo de séculos. Apenas quando esta dialética da sociedade burguesa atingiu seus estágios tardios, o fascismo se tornou uma possibilidade objetiva e então uma realidade histórica catastrófica. ${ }^{37}$ Em contraste com muitos teóricos "progressistas" e "evolucionários" no período pós-Segunda Guerra, que atribuíram o sucesso do fascismo na Alemanha e na Itália a um Sonderweg - ou seja, a um "déficit de modernização" em comparação com outras democracias ocidentais - Horkheimer e os Teóricos Críticos reconheceram que o fascismo havia brotado de algumas das tendências mais profundas e poderosas dormentes nas sociedades capitalistas modernas e que essas tendências não haviam sido removidas pela rendição incondicional dos fascistas em 1945. A reformulação de Adorno do imperativo categórico kantiano nos anos 1960 - "a humanidade não

37 Para uma discussão do conceito de "dialética da sociedade burguesa", que elaborei como uma descrição de certos pressupostos históricos e teóricos chave que guiam o trabalho inicial de Horkheimer, ver Abromeit, 2011, pp.394-95, 425-32. 
livre [deve] organizar seus pensamentos e ações para que Auschwitz não se repita, para que nada parecido aconteça” - expressava sua convicção de que, mesmo com as democracias liberais do pós-guerra, tais tendências ainda existiam. Mesmo que se questione, como eu, as afirmações de que o Tea Party ou até mesmo o mais explicitamente autoritário Donald Trump possam ser descritos como "fascistas", a percepção dos Teóricos Críticos de que o fascismo representa uma forma extrema das tendências populistas de direita, que têm profundas raízes em sociedades capitalistas modernas, fornece um corretivo muito importante para as abordagens ingênuas e ahistóricas do populismo de direita e do autoritarismo, que foram pegas de surpresa por seu recente ressurgimento nos Estados Unidos. A Teoria Crítica oferece uma explicação muito mais incisiva do que as abordagens ahistóricas da (não tão) surpreendente persistência do populismo de direita no século XXI.

Exemplo das abordagens historicamente ingênuas podem ser encontrados em diversos ensaios jornalísticos sobre Trump que descrevem a recente "redescoberta" do autoritarismo entre cientistas sociais acadêmicos dos Estados Unidos. Em vez de explorar os méritos e deméritos desta literatura aqui, gostaria apenas de chamar atenção para a desconsideração, notavelmente displicente, de todo os estudos dos Teóricos Críticos sobre o autoritarismo. Por exemplo, em março de 2016, Amanda Taub publicou um artigo amplamente discutido no periódico online Vox, que explorou esses novos trabalhos sobre o autoritarismo e as suas implicações para a compreensão do surpreendente sucesso de Donald Trump. Sua irrefletida confiança na marcha adiante do progresso nas ciências sociais transparece nas seguintes afirmações: “após um período de junk science em meados do século XX, um grupo mais sério de pesquisadores abordou esta questão, estudando especificamente como isso se dá na política dos Estados Unidos”. Eliminado qualquer dúvida acerca dos culpados em questão, Taub continua:

o trabalho inicial não era particularmente rigoroso para os padrões de hoje. 0 teórico crítico Theodor Adorno, por exemplo, desenvolveu o que ele denominou a "escala F", que procurou medir as tendências fascistas. O teste não era acurado. Respondentes sofisticados podiam rapidamente descobrir quais era as respostas “corretas" e manipular o teste. E não havia prova de que o tipo de personalidade que supostamente media de fato apoiava o fascismo (Taub, 2016).

Felizmente, no entanto,

no começo dos anos 1990, um cientista político chamado Stanley Feldman mudou tudo. (...) Ele percebeu que se o autoritarismo fosse um perfil de personalidade em vez de apenas uma preferência política, ele poderia fazer com que os respondentes revelassem estas tendências ao fazer questões sobre um tópico que parecia muito menos controverso: (...) metas parentais (Taub, 2016).

As caracterizações de Taub aqui não são incomuns; pode-se encontrar afirmações muito similares em diversos artigos recentes sobre o autoritarismo e Trump. Infelizmente, 
refletem nada mais do que as atuais ideias errôneas sobre os estudos sofisticados e substanciais do Instituto sobre o autoritarismo. Muitas das supostas deficiências de seus trabalhos, que são mencionadas por Taub e por outros, foram, na verdade, parte integral dos métodos empregados por eles. Por exemplo, a suposta descoberta em trabalhos mais recentes das atitudes em relação à educação de crianças como um indicador chave do autoritarismo foi empregado em muitos dos estudos do Instituto. ${ }^{38}$ Não é preciso refutar a absurda afirmação de que o Instituto via o autoritarismo como uma preferência política em vez de uma complexa constelação de traços de caráter, dado que esta era a hipótese mais básica operante em $A$ personalidade autoritária. Além disso, Adorno e outros membros do Instituto nunca cometeram o erro de assumir que o autoritarismo coincidia de modo simples com visões políticas "esquerda" ou direita", ou "liberal” ou "conservadora”, como a discussão acima do pseudoconservadorismo deve ter esclarecido. A discussão dos Teóricos Críticos da "rebelião conformista", motivada pela fraqueza do ego, e não por percepções críticas, é outro exemplo - desta vez de uma posição “pseudocrítica”. Finalmente, desde o início, eles reconheceram claramente a necessidade de obter informação empírica sobre o autoritarismo indiretamente, para evitar autocensura entre os respondentes. Sua habilidade psicanalítica os auxiliou enormemente em desenvolver técnicas crescentemente refinadas para obter acesso não apenas às atitudes abertamente professadas pelos participantes em seus estudos, mas também àquelas privadas ou até mesmo inconscientes. ${ }^{39}$

$O$ ressurgimento de um poderoso movimento populista de direita nos EUA na sequência da Grande Recessão de 2008, a mais recente expansão daquele movimento pseudoconservador e a intensificação dos aspectos autoritários de sua retórica deveriam ser o sinal para recuperar os importantes insights dos Teóricos Críticos sobre as raízes do populismo autoritário nas sociedades capitalistas modernas, que podem ainda contribuir imensamente para explicar sua persistência do século XX até o século XXI. A reação mais comum da ciência social contemporânea, historicamente míope, ao Tea Party e, especialmente, ao sucesso de Donald Trump tem sido de surpresa constrangida. 0 ressurgimento do populismo de direita - primeiro na

38 Já no primeiro grande estudo empírico do Instituto - sobre as atitudes dos trabalhadores de colarinho azul e branco na Alemanha de Weimar - Horkheimer e Fromm incluíram questões sobre a educação de crianças como um indicador indireto de um autoritarismo manifesto ou latente. Em seu principal projeto empírico, os Estudos sobre autoridade e família, atitudes relativas à educação de crianças foram mais uma vez centrais, como o título sugere. Em estudos posteriores, elas também desempenharam um papel central, mas os Teóricos Críticos eram muito sofisticados para acreditar que as atitudes em relação à educação de crianças sozinhas bastavam para prover indicações confiáveis de predisposições autoritárias.

39 Para uma discussão destas técnicas, ver minha resenha da primeira tradução para o inglês de "Group Experiment", o primeiro grande estudo empírico do Instituto após seu reestabelecimento em Frankfurt após a Segunda Guerra Mundial. Cf. Abromeit, $2013 a$. 
Europa e agora nos EUA - durante a consolidação e, mais recentemente, a crise do capitalismo global neoliberal, dificilmente virá como uma surpresa para qualquer um familiar com os estudos dos Teóricos Críticos do autoritarismo. Mas, por diversas razões, a memória destes estudos foi enfraquecida substancialmente no presente. A tentativa de teóricos mais recentes na Alemanha - que orgulhosamente se situam na tradição da "Escola de Frankfurt", enquanto ao mesmo tempo negam a relevância contemporânea de seus fundadores -, de situar a Teoria Crítica em firmes bases "normativas", tem desviado a atenção de tendências catastróficas existentes. Como os socialistas utópicos do passado, os teóricos normativos pensam que podem ditar como a sociedade deveria estar se desenvolvendo, mas eles não podem explicar porque ela está na verdade se movendo na direção oposta. Como visto, Horkheimer e seus colegas estavam convencidos de que a ameaça do autoritarismo era mínima no período imediatamente pós-guerra, e de que a prosperidade econômica e a relativa segurança dos anos 1950 e 1960 continuou a refrear a ameaça. Mas os crescentes níveis de desigualdade, frustração e ansiedade desde os anos 1970 criaram condições muito mais favoráveis para os movimentos populistas de direita. Então, mesmo se a memória dos estudos dos Teóricos Críticos do autoritarismo e do populismo de direita tenha se tornado fraca, devemos nos voltar a eles neste momento de perigo.

\section{Referências}

Abromeit, J. (2011). Max Horkheimer and the Foundations of the Frankfurt School. New York: Cambridge University Press.

. (2013). Whiteness as a Form of Bourgeois Anthropology? Historical Materialism and Psychoanalysis in the Work of David Roediger, Max Horkheimer, Erich Fromm, and Herbert Marcuse. Radical Philosophy, 16(1), pp.325-343.

. (2013a). Review of "Friedrich Pollock and Theodor W. Adorno, Group Experiment and Other Writings: The Frankfurt School on Public Opinion in Postwar Germany". Journal of Modern History, 85(1), pp.161-168

(2016). "Transformations of Producerist Populism in Western Europe". In: Transformations of Populism in Europe and the Americas: History and Recent Tendencies. J. Abromeit, B. Chesterton, Y. Norman and G. Marotta (eds.). London and New York: Bloomsbury.

Adorno, T.; Frenkel-Brunswik, E; Levinson, D. J.; Sanford, R. N. (1950). The Authoritarian Personality. New York: Harper \& Brothers.

Adorno, T. (1969). "Scientific Experiences of a European Scholar in America". In: D. Fleming and B. Bailyn (eds.). The Intellectual Migration: Europe and America, 1930-1960. Cambridge, MA: Harvard University Press.

(1977). “Über Tradition”. In: Rolf Tiedemann (ed.). Gesammelte Schriften, vol. 10.1. Frankfurt a.M.: Suhrkamp. 
(1998). "The Meaning of Working through the Past". In: Critical Models: Interventions and Catchwords. Edited and translated by Henry Pickford. New York: Columbia University Press.

. (1998a). "Vorlesungen zur Ästhetik (1967)". Wolfgang Kraushaar (ed.). Frankfurter Schule und Studentenbewegung, vol. 2. Hamburg: Zweitausandeins.

Benjamin, W. (1968). “Theses on the Philosophy of History”. In: Illuminations. Hannah Arendt (ed). Translated by Harry Zohn. New York: Schocken.

Formisano, R. (2012). The Tea Party: A Brief History. Baltimore: Johns Hopkins University Press.

Fritzsche, P. (1998). Germans into Nazis. Cambridge, MA: Harvard University Press.

Fromm, E. (1983). Arbeiter und Angestellte am Vorabend des Dritten Reiches: Eine sozialpsychologische Untersuchung. Wolfgang Bonss (ed.). Munich: Deutscher Taschenbuch Verlag, 1983.

Hobsbawm, E. (1994). The Age of Extremes: A History of the World, 1914-1991. New York: Vintage Books.

Horkheimer, M. (1949). "Introduction”. In: Lowenthal, L. and Guterman, N. Prophets of Deceit: A Study of the Techniques of the American Agitator. New York: Harper \& Brothers.

- (1993). "Egoism and Freedom Movements: On the Anthropology of the Bourgeois Epoch”. In: Between Philosophy and Social Science: Selected Early Writings. Translated by G.F. Hunter, M.S. Kramer and J. Torpey. Cambridge, MA: MIT Press.

Jay, M. (1982). Introduction to Horkheimer. Telos, 54, pp.5-9.

Lepore, J. (2010). The White of Their Eyes: The Tea Party's Revolution and the Battle over American History. Princeton and Oxford: Princeton University Press.

Lowenthal, L. and Guterman, N. (1949). Prophets of Deceit: A Study of the Techniques of the American Agitator. New York: Harper \& Brothers.

Mudde, C. (2016). “Populist Radical Right Parties in Europe Today”. In: Transformations of Populism in Europe and the Americas: History and Recent Tendencies. J. Abromeit, B. Chesterton, Y. Norman and G. Marotta (eds.). London and New York: Bloomsbury.

Piketty, T. (2014). Capital in the Twenty-First Century. Cambridge, MA: Harvard University Press.

Polanyi, K. (1944). The Great Transformation. New York: Rinehart.

Postone, M; and Brick, B. (1993). "Critical Theory and Political Economy". In: S. Benhabib, W. Bonss and J. McCole (eds.). On Max Horkheimer: New Perspectives. Cambridge, MA: MIT Press.

Skocopl, T. \& Williams, V. (2012). The Tea Party and the Remaking of American Conservatism. New York: Oxford University Press.

Taub, A. (2016). The rise of American Authoritarianism. Vox. http://www.vox. com/2016/3/1/11127424/trump-authoritarianism (acessado em: 16.02.2016). 
John Abromeit

Worrell, M. (2008). Dialectic of Solidarity: Labor, Antisemitism and the Frankfurt School. Chicago: Haymarket Books.

Ziege, E.-M. (2009). Antisemitismus und Gesellschaftstheorie: Die Frankfurter Schule im amerikanischen Exil. Frankfurt a.M.: Suhrkamp.

Recebido em: 30.04.2017 Aceito em: 09.06.2017

Tradução de Simone Fernandes (Universidade de São Paulo, São Paulo, Brasil) 